\title{
Fetal Hypoxia
}

National Cancer Institute

\section{Source}

National Cancer Institute. Fetal Hypoxia. NCI Thesaurus. Code C50564.

Hypoxia in utero, caused by conditions such as inadequate placental function (often

abruptio placentae), preeclamptic toxicity, prolapse of the umbilical cord, or complications from anesthetic administration. 